\title{
Benefit of Growth Hormone Replacement in Adults Older than 60 Years
}

\author{
Kristin Arp $^{1 \dagger}$, Christian Schwahn ${ }^{1 \dagger}$, Nele Friedrich ${ }^{1}$, Thomas Kohlmann², Jörn Moock ${ }^{2}$, \\ Maria Koltowska-Häggström ${ }^{3}$, Matthias Nauck ${ }^{1}$, Michael Buchfelder ${ }^{4 \#,}$ \\ Henri Wallaschofski ${ }^{1 \text { H† }}$, Christin Spielhagen ${ }^{1 \dagger}$ \\ ${ }^{1}$ Institute of Clinical Chemistry and Laboratory Medicine, University Medicine Greifswald, Greifswald, Germany \\ ${ }^{2}$ Community Medicine, University Medicine Greifswald, Greifswald, Germany \\ ${ }^{3}$ KIGS/KIMS/ACROSTUDY Medical Outcomes, Pfizer Endocrine Care, Sollentuna, Sweden \\ ${ }^{4}$ Department of Neurosurgery, University of Erlangen, Erlangen, Germany \\ Email: henri.wallaschofski@uni-greifswald.de
}

Received April 11, 2013; revised May 15, 2013; accepted June 15, 2013

Copyright (C) 2013 Kristin Arp et al. This is an open access article distributed under the Creative Commons Attribution License, which permits unrestricted use, distribution, and reproduction in any medium, provided the original work is properly cited.

\begin{abstract}
Objective: Benefits of replacement therapy in growth hormone deficiency (GHD) are well documented in younger and middle-aged patients. The aim of our investigation was to prove the benefit of GH replacement for patients older than 60 years especially in terms of health-related quality of life (HRQoL) of age as well. Design: Data of 743 consecutively recruited patients (394 men, 349 women) with GHD aged $20-49(n=606)$ and $60-69(n=137)$ years enrolled from KIMS Germany (Pfizer International Metabolic Database) were compared. Treatment effects over the 12 months dose-finding and the subsequent phase up to three years were analysed using mixed models. Serum insulin-like growth factor I (IGF-I), fasting blood glucose, fasting serum total cholesterol and low-density lipoprotein cholesterol (LDL-C) as well as body mass index (BMI) at baseline and at last visit were studied. HRQoL was assessed using the Quality of Life-Assessment of Growth Hormone Deficiency in Adults (QoL-AGHDA). Results: For both age groups and genders the IGF-I level and standardized IGF-I increased over the dose-finding phase. In women, the overall QoL-AGHDA score at the baseline examination was 8.7 (95\% CI: 7.7 - 9.7) and decreased to 6.3 (95\% CI: 5.1 - 7.6) at the end of the dose-finding phase $(\mathrm{p}<0.001)$. In men, the corresponding values were $8.8(95 \%$ CI: $7.8-9.8)$ and 6.4 (95\% CI: 5.1 7.6; $\mathrm{p}<0.001)$ without differences between the age groups. The therapy benefit for elderly was supported by the non-impairment after the dose-finding phase. In total cholesterol, LDL-C and fasting blood glucose, no significant changes were detected, whereas an increase in BMI did not differ between age groups. Conclusion: We could show positive effects of GH replacement on HRQoL in patients older than 60 years of age. Therefore, GH replacement should be considered in elderly GHD adults without difference compared to younger age groups.
\end{abstract}

Keywords: Growth Hormone Deficiency; Quality of Life; Growth Hormone; IGF-I

\section{Introduction}

Growth hormone deficiency (GHD) in adults is a wellrecognized distinct clinical condition resulting from partial or complete pituitary failure and is characterized by increased fat mass [1], a decrease in lean body mass [2] and bone mineral density [3] as well as abnormal lipid metabolism $[4,5]$. Together, this metabolic changes result in an increased cardiovascular risk [6-9]. One of the most important impairment from a patient's point of view,

"This research did not receive any specific grant from any funding agency in the public, commercial or not-for-profit sector.

\# On behalf of the German KIMS board.

${ }^{\dagger}$ Arp, Schwahn, Wallaschofski and Spielhagen contributed equally. however, is the decline in health-related quality of life (HRQoL) [10,11].

The availability of biosynthetic human growth hormone $(\mathrm{GH})$ has made it possible to explore the effects and benefits of GH replacement therapy in adults with GHD. Some therapy effects, such as those on body competition or lipids, may be phase-specific. Recently, we demonstrated long-term beneficial effects of GH replacement therapy on HRQoL and showed no significant effects on total cholesterol, low-density lipoprotein cholesterol (LDL-C) or body mass index (BMI) [12]. For quality of life, only a few studies compared patients concerning short term GH responsiveness across older age- 
groups [13-16].

As the benefit for young and middle-aged patients is well-known, here we hypothesized a benefit for patients aged 60 years or older as well, possibly to a lower degree. Therefore, we analysed data from a German KIMS (Pfizer International Metabolic Database) population with a statistical method designed to handle intermittent missing observations.

\section{Subjects and Method}

\subsection{Patient Characteristics}

We analysed baseline and long-term data (range: 2 - 4 years) of 743 consecutively documented patients (394 men and 349 women) with GHD, aged 20 to 69 years, enrolled in KIMS Germany. The inclusion criterion for KIMS was the presence of GHD, confirmed by a relevant stimulation test. The therapy performance was monitored by the treating physicians. However, after an examination at baseline, the success of the therapy was individually adjusted in relation to IGF-I values, assuming one year for the dose-finding phase, in accordance with the guidelines [17,18]. An examination at the end of the dose-finding phase and a minimum of one visit per year were mandatory for each patient. Due to a change of IGF-I assays, 31st December 2005 was the qualifying date for the last examination. To analyse an observation period up to 4 years patients from March 1992 until 31st December 2001 were included. Sophisticated statistical models, namely mixed models, were used to deal with missing values. In women 1227.1 person-years and in men 1356.4 person-years of follow-up were observed. The mean time between the first and the last examination was $3.5 \pm 0.8$ years for female and $3.4 \pm 0.9$ years for male patients.

We analysed the causes of GHD at baseline in the 743 KIMS patients (Table 1). Childhood-onset (CO) GHD was reported in 192 patients ( 75 women and 117 men). Most patients ( $\mathrm{n}=551 ; 274$ women and $277 \mathrm{men})$ had adult-onset (AO) GHD. The majority of patients had additional pituitary hormone replacement therapy at baseline. We detected adrenocorticotropic deficiency in $66.0 \%$ of patients aged $20-49$ years and in $67.2 \%$ of patients aged $60-69$ years. Therapy with thyroid hormones received $73.9 \%$ of patients aged $20-49$ years and $69.3 \%$ of patients aged 60 - 69 years. Differentiation between thyrotrophic deficiency and thyroid disease was not possible. Therapy with sex hormones received $77.3 \%$ of male patients aged 20 - 49 years and $87.7 \%$ of male patients aged $60-69$ years and $59.0 \%$ women aged $20-49$ years and $41.1 \%$ of female patients aged $60-69$ years. Therapy with sex hormones included any indication. Antidiuretic hormone was deficient in $30.4 \%$ of patients aged 20 - 49 years and in $13.9 \%$ of patients aged $60-69$ years.

Table 1. Etiology of growth hormone deficiency in 743 patients.

\begin{tabular}{|c|c|c|c|c|}
\hline & \multicolumn{2}{|c|}{$20-49$ years $(n=606)$} & \multicolumn{2}{|c|}{$60-69$ years $(n=137)$} \\
\hline & $\mathrm{n}$ & $\%$ & $\mathrm{n}$ & $\%$ \\
\hline Idiopathic & 74 & 12.2 & 5 & 3.6 \\
\hline Congenital & 15 & 2.5 & 1 & 0.7 \\
\hline Non-functioning adenoma & 131 & 21.6 & 87 & 63.5 \\
\hline \multicolumn{5}{|l|}{ Hormone secreting adenoma } \\
\hline Prolactinoma & 61 & 10.1 & 8 & 5.8 \\
\hline ACTH-om/Cushings diseases & 35 & 5.8 & 5 & 3.6 \\
\hline GH-om & 8 & 1.3 & 1 & 0.7 \\
\hline TSH-om & 0 & 0.0 & 1 & 0.7 \\
\hline Gonadotropin-secreting & 2 & 0.3 & 0 & 0.0 \\
\hline Craniopharyngioma & 107 & 17.7 & 8 & 5.8 \\
\hline Tumor nearby pituitary/hypothalamus & 25 & 4.1 & 3 & 2.2 \\
\hline Pituitary abscess & 2 & 0.3 & 0 & 0.0 \\
\hline Rathke cyst & 12 & 2.0 & 1 & 0.7 \\
\hline Hypophysitis & 8 & 1.3 & 2 & 1.5 \\
\hline Traumatic brain injury & 35 & 5.8 & 1 & 0.7 \\
\hline Sheehan syndrome & 19 & 3.1 & 4 & 2.9 \\
\hline Empty sella syndrome & 14 & 2.3 & 6 & 4.4 \\
\hline Cranial tumor distant from pituitary/hypothalamus & 16 & 2.6 & 2 & 1.5 \\
\hline CNS infection & 8 & 1.3 & 0 & 0.0 \\
\hline Granulomatous diseases & 3 & 0.5 & 0 & 0.0 \\
\hline Vascular diseases & 3 & 0.5 & 1 & 0.7 \\
\hline Others & 28 & 4.6 & 1 & 0.7 \\
\hline
\end{tabular}


Patients were examined for IGF-I, fasting blood glucose, total cholesterol, LDL-C, BMI and HRQoL at baseline (Tables 2 and 3) and at the last follow-up visit. BMI was calculated based on height and body weight. HRQoL was determined using the adult GH deficiency assessment (QoL-AGHDA) score. This is a cross-cultural, disease-specific, one-dimensional, patient needs-based questionnaire specifically developed for GHD patients [19]. QoL-AGHDA focuses on those aspects of HRQoL that seem most relevant to adult GHD patients and detects deficits in areas that are affected in adults with GHD.

\subsection{Laboratory Methods}

Blood samples were drawn to measure IGF-I, glucose, total cholesterol and HDL-C. LDL-C were estimated using Friedewald's formula [20]. Serum lipoproteins and IGF-I were measured centrally in the KIMS laboratory as described previously [21-23]. Until November 2002, serum IGF-I was determined by radioimmunoassay after acid-ethanol precipitation of IGF-binding proteins (Nichols Institute Diagnostics, San Juan Capistrano, CA, USA). Thereafter, a chemiluminescence immunoassay (Nichols Advantage System, San Clemente, CA, USA) was introduced. IGF-I values were adjusted for age and gender and expressed as standardized deviation score (SDS). Blood glucose was analysed locally by routine laboratory techniques.

\subsection{Statistical Analysis}

In preliminary analyses, patients were classified into age groups of ten years. The available data from age group of 50 - 59 years were too small $(n=3)$ to estimate effects of desirable precision and therefore excluded for further analysis. To facilitate the readability we decided to present two age groups: younger than 50 years and older than 60 years. According to the study guideline the period of $\mathrm{GH}$ replacement therapy of four years was divided into a dose-finding phase over the first 12 months and the following preservation phase over three years.

Analyses were performed with STATA/MP software, version 10.1 (StataCorp LP, College Station, Texas, USA). Baseline characteristics are expressed as mean and standard deviation (SDS). Solely to show a proxy for the estimated change, we present time points for descriptive statistics and figures. Time was rounded up to the nearest year, except for the baseline examination and within the first year (which was rounded up to the half-year). The 95\% confidence intervals (CI) were adjusted for clusters in patients using the "mean" procedure.

To estimate changes in IGF-I levels or other outcomes we took the exact time (years with appropriate number of digits) by using linear mixed models instead of rounded time points, as done in conventional models. Mixed mo- dels use all available data, properly account for correlation between repeated measurements and properly deal with missing data if the missing at random (MAR) assumption is met. In longitudinal studies, however, it is often reasonable to assume that the intermittent missing observations are randomly missing [24]. For missing baseline values, corresponding tests were performed in preliminary analyses. As the number of missing values at each examination differed across outcomes, the available numbers of patients and observations were presented outcome-specifically at the place of the given analysis.

For the dose-finding phase and the preservation phase, we modeled slopes for the change in levels of each dependent variable, resulting in a so-called discontinuous slope model, described by Singer et al. [25]. To model the baseline value, we included the intercept and age at baseline as fixed effects. To quantify the change over the two phases adequately, we included continuous time and continuous time after 1 year as fixed effects. Continuous time, continuous time after 1 year and the intercept were included as variance components or random effects. To obtain the change over the second phase the corresponding linear combination was computed. For the linear mixed models we used the GLLAMM [26] procedure. The assumptions of the models were examined analytically and graphically and were adequately met, except for QoL-AGHDA score as an outcome. Therefore, results of negative binomial regression models were presented for QoL-AGHDA. An improvement in QoL-AGHDA is indicated by negative coefficients. For the negative binomial regression the "xtnbreg" procedure was used.

\section{Results}

\subsection{GH Dose}

The dose of GH increased over the dose-finding phase and was nearly constant over the preservation phase. The mean dose of $\mathrm{GH}$ at the beginning of preservation phase was $0.42 \pm 0.01 \mathrm{mg}$ per day for females $(\mathrm{n}=531)$ and $0.40 \pm 0.02 \mathrm{mg}$ per day for males $(\mathrm{n}=563)$ for patients aged 20 - 49 years. For the elderly the mean dose of GH at the beginning at the preservation phase was $0.25 \pm$ $0.03 \mathrm{mg}$ per day in females $(\mathrm{n}=105)$ and $0.30 \pm 0.02 \mathrm{mg}$ per day in males $(n=149)$.

\subsection{Serum IGF-I}

The detailed results are presented in Table $\mathbf{4}$ and Figures 1(c) and (d). The baseline IGF-I values (Tables 2 and 3) did not differ across age groups (females: $p=0.557$; males: $\mathrm{p}=0.699$ ) whereas standardized IGF-I values differed (both genders: $\mathrm{p}<0.01$ ). For both age groups and genders, the IGF-I absolute concentrations and IGF-I SDS increased over the dose-finding phase. In females 


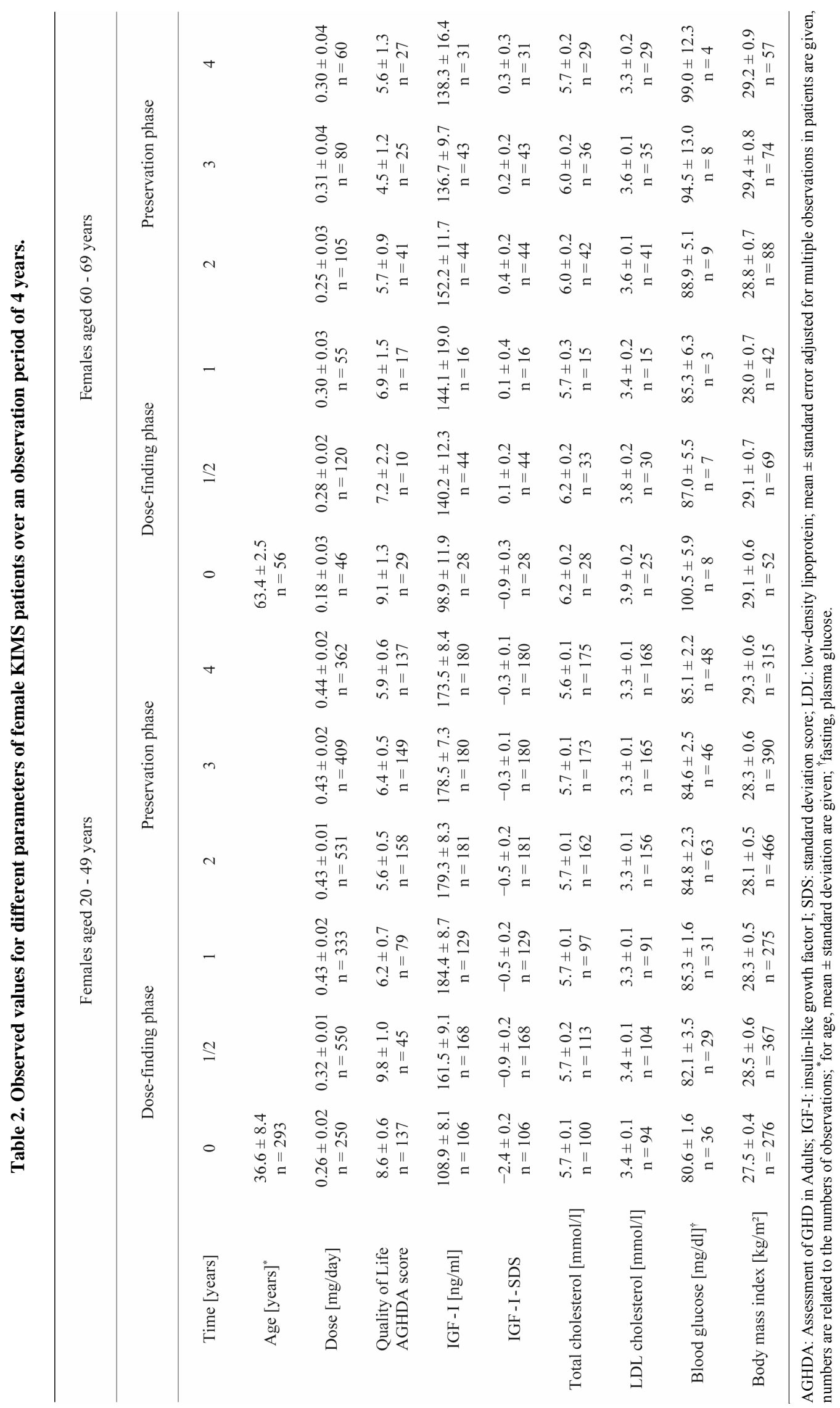




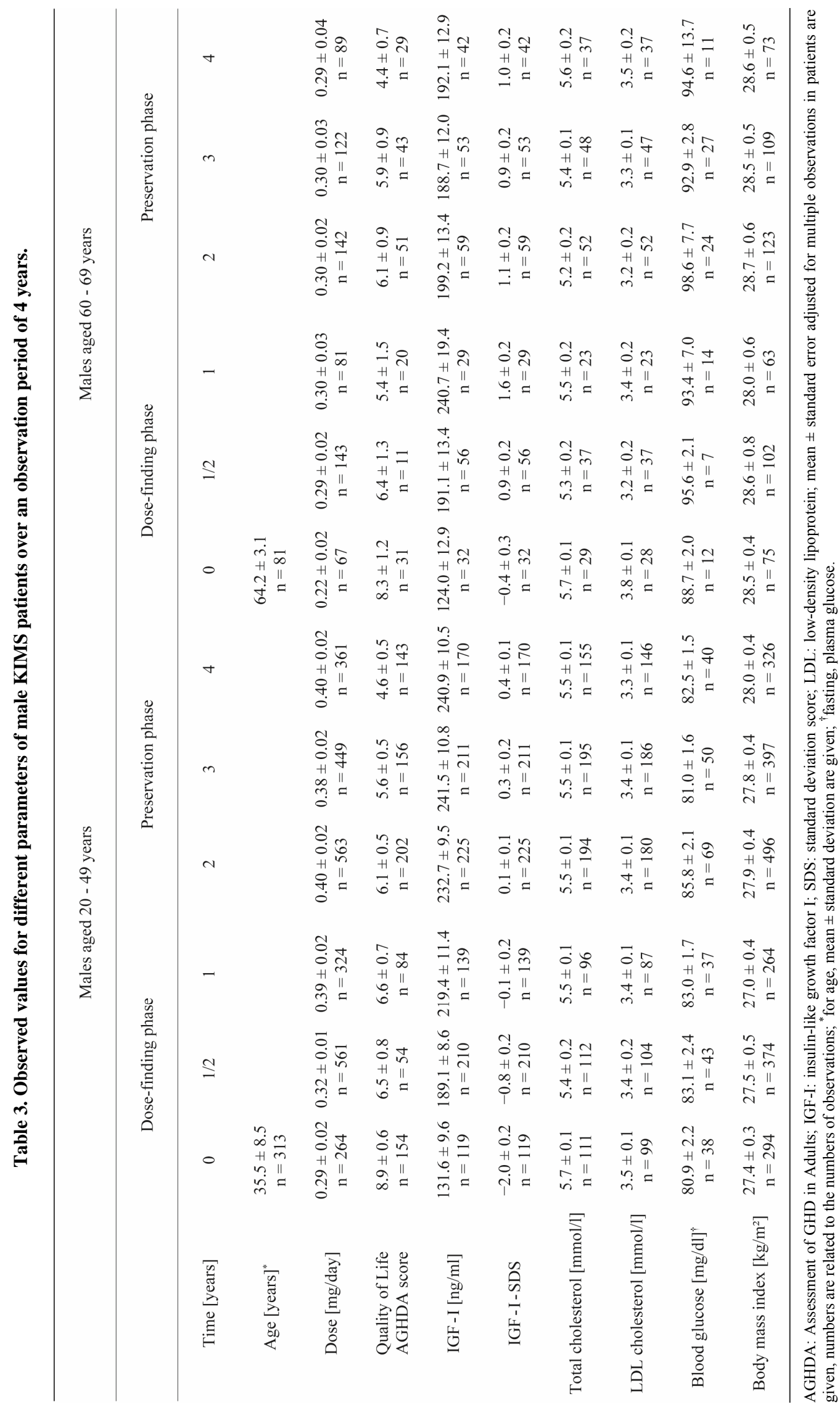


Table 4. IGF-I and standardized IGF-I across time for females and males: coefficients or linear combinations and standard errors of changes (linear mixed models).

\begin{tabular}{|c|c|c|}
\hline & \multicolumn{2}{|c|}{ Age group } \\
\hline & $20-49$ years & $60-69$ years \\
\hline \multicolumn{3}{|c|}{ IGF-I } \\
\hline Females ( $n=272 ; 1150$ observations) & $(\mathrm{n}=227 ; 944$ obs. $)$ & $(\mathrm{n}=45 ; 206$ obs. $)$ \\
\hline \multicolumn{3}{|l|}{ Dose-finding phase } \\
\hline Change & $66.8(8.0)^{\ddagger}$ & $36.5(16.6)^{*}$ \\
\hline Difference in change compared with group aged 20 - 49 years & --- & $-30.3(18.5)$ \\
\hline \multicolumn{3}{|l|}{ Preservation phase } \\
\hline Change & $-10.8(3.7)^{\dagger}$ & $-7.6(8.5)$ \\
\hline Difference in change compared with group aged $20-49$ years & --- & $3.1(9.3)$ \\
\hline Males ( $n=303 ; 1345$ observations) & $(\mathrm{n}=239 ; 1074$ obs. $)$ & $(\mathrm{n}=64 ; 271$ obs. $)$ \\
\hline \multicolumn{3}{|l|}{ Dose-finding phase } \\
\hline Change & $74.8(8.4)^{\ddagger}$ & $61.6(16.5)^{\ddagger}$ \\
\hline Difference in change compared with group aged $20-49$ years & --- & $-13.2(18.6)$ \\
\hline \multicolumn{3}{|l|}{ Preservation phase } \\
\hline Change & $-4.0(3.9)$ & $-9.5(8.2)$ \\
\hline Difference in change compared with group aged $20-49$ years & --- & $-5.5(9.1)$ \\
\hline \multicolumn{3}{|c|}{ IGF-I standardized } \\
\hline \multicolumn{3}{|l|}{ Females ( $n=272 ; 1150$ observations) } \\
\hline \multicolumn{3}{|l|}{ Dose-finding phase } \\
\hline Change & $1.6(0.2)^{\ddagger}$ & $0.9(0.3)^{\dagger}$ \\
\hline Difference in change compared with group aged $20-49$ years & --- & $-0.7(0.4)^{*}$ \\
\hline \multicolumn{3}{|l|}{ Preservation phase } \\
\hline Change & $-0.1(0.1)$ & $0.0(0.1)$ \\
\hline Difference in change compared with group aged 20 - 49 years & --- & $0.1(0.2)$ \\
\hline \multicolumn{3}{|l|}{ Males ( $n=303 ; 1345$ observations) } \\
\hline \multicolumn{3}{|l|}{ Dose-finding phase } \\
\hline Change & $1.5(0.2)^{\ddagger}$ & $1.1(0.3)^{\ddagger}$ \\
\hline Difference in change compared with group aged 20 - 49 years & --- & $-0.4(0.3)$ \\
\hline \multicolumn{3}{|l|}{ Preservation phase } \\
\hline Change & $0.0(0.1)$ & $-0.1(0.1)$ \\
\hline Difference in change compared with group aged 20 - 49 years & --- & $-0.1(0.1)$ \\
\hline
\end{tabular}

${ }^{*} \mathrm{p}<0.05 ;{ }^{\dagger} \mathrm{p}<0.010 ;{ }^{\dagger} \mathrm{p}<0.001$. 
the change during the dose-finding phase was greater in the group aged 20 - 49 years compared with the older age group. In males no age-related change occurred. The possibly relevant difference in change of IGF-I levels between males and females did not reach statistical significance, neither for elderly nor for non-elderly. Over the preservation phase, changes in standardized IGF-I were not statistically significant.

\subsection{HRQoL}

In each age group of both genders the QoL-AGHDA score decreased over the dose-finding phase and remained stable over the preservation phase except for females younger than 50 years of age (Table 5, Figures 1(a) and (b)). In males and females the rates of QoL-AGHDA score over the dose-finding phase were almost the same in both age groups. Females showed a higher rate of reduction of QoL-AGHDA-scores than males $(\mathrm{p}=0.045$; 647 subjects). In women the overall observed mean QoLAGHDA score at the baseline examination was 8.7 (95\% CI: 7.7 - 9.7) and decreased to $6.3(95 \% \mathrm{CI}: 5.1$ - 7.6) at the end of the dose-finding phase $(\mathrm{p}<0.001)$. In men the overall mean QoL-AGHDA score decreased from 8.8 (95\% CI: $7.8-9.8)$ at the baseline examination to 6.4 (95\% CI: $5.1-7.6)$ at the end of the dose-finding phase $(\mathrm{p}<0.001)$. In ancillary analyses we included the onset of GHD ( $\mathrm{CO}$ and $\mathrm{AO}$ ) in the model. Differences in change between the two onset groups did not occur. But over the total period of four years the QoL-AGHDA score was lower in subjects with $\mathrm{CO}$ than in those with $\mathrm{AO}$ (difference in females: 0.57, 95\% CI: 0.21 - 0.93; $\mathrm{p}=$ 0.002 ; difference in males: $0.32,95 \% \mathrm{CI}: 0.02-0.62 ; \mathrm{p}=$ 0.034).

\subsection{Blood Glucose, Lipid Profile and Anthropometry}

For total cholesterol and LDL-C, glucose and BMI a discontinuous slope model is not needed but a linear model with one single slope over both phases can be assumed. To examine phase-specific relationships we analyzed discontinuous slope models as well. For blood glucose and lipids we did not find statistically significant changes.

Changes in BMI did not differ across age groups. The overall estimates yielded no relevant changes over dosefinding phase (females: $0.04 \mathrm{~kg} / \mathrm{m}^{2}, 95 \% \mathrm{CI}$ : $-0.22-0.29$, $\mathrm{p}=0.769, \mathrm{n}=349$ with 2471 observations; males: 0.08 $\mathrm{kg} / \mathrm{m}^{2}, 95 \% \mathrm{CI}:-0.12-0.27, \mathrm{p}=0.426, \mathrm{n}=394$ with 2696 observations). Over the preservation phase females and males similarly increased in BMI (females: 0.30 $\mathrm{kg} / \mathrm{m}^{2}$ per year, 95\% CI: $0.17-0.44, \mathrm{p}<0.001$; males: $0.29 \mathrm{~kg} / \mathrm{m}^{2}$ per year, $\left.95 \% \mathrm{CI}: 0.18-0.39, \mathrm{p}<0.001\right)$.

\section{Discussion}

Positive effects of GH replacement therapy in GHD patients are widely accepted [17]. Here, we demonstrate positive therapy effects on HRQoL in a large cohort of

Table 5. AGHDA score across time for females and males: coefficients or linear combinations and standard errors of changes (Negative binomial regression).

\begin{tabular}{|c|c|c|}
\hline & \multicolumn{2}{|c|}{ Age group } \\
\hline & $20-49$ years & $60-69$ years \\
\hline Females ( $n=298 ; 854$ observations) & $(\mathrm{n}=248 ; 705$ obs. $)$ & $(\mathrm{n}=50 ; 149$ obs. $)$ \\
\hline \multicolumn{3}{|l|}{ Dose-finding phase } \\
\hline Change & $-0.54(0.06)^{\ddagger}$ & $-0.53(0.13)^{\ddagger}$ \\
\hline Difference in change compared with group aged $20-49$ years & --- & $-0.01(0.14)$ \\
\hline \multicolumn{3}{|l|}{ Preservation phase } \\
\hline Change & $0.06(0.03)^{*}$ & $-0.06(0.07)$ \\
\hline Difference in change compared with group aged 20 - 49 years & --- & $-0.12(0.08)$ \\
\hline Males ( $n=349 ; 978$ observations) & $(\mathrm{n}=277 ; 793$ obs. $)$ & $(\mathrm{n}=72 ; 185$ obs. $)$ \\
\hline \multicolumn{3}{|l|}{ Dose-finding phase } \\
\hline Change & $-0.34(0.05)^{\ddagger}$ & $-0.37(0.11)^{\dagger}$ \\
\hline Difference in change compared with group aged 20 - 49 years & --- & $-0.03(0.12)$ \\
\hline \multicolumn{3}{|l|}{ Preservation phase } \\
\hline Change & $-0.02(0.03)$ & $-0.02(0.06)$ \\
\hline Difference in change compared with group aged 20 - 49 years & --- & $0.00(0.06)$ \\
\hline
\end{tabular}

${ }^{*} \mathrm{p}<0.05 ;{ }^{\dagger} \mathrm{p}<0.010 ;{ }^{\dagger} \mathrm{p}<0.001$. 

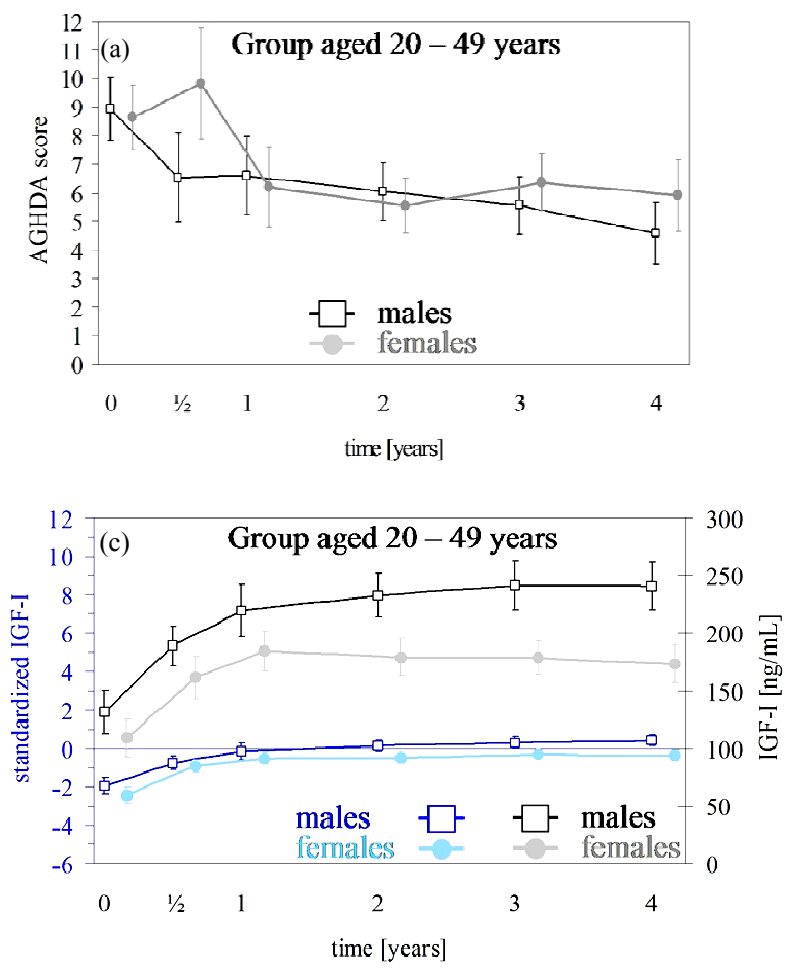
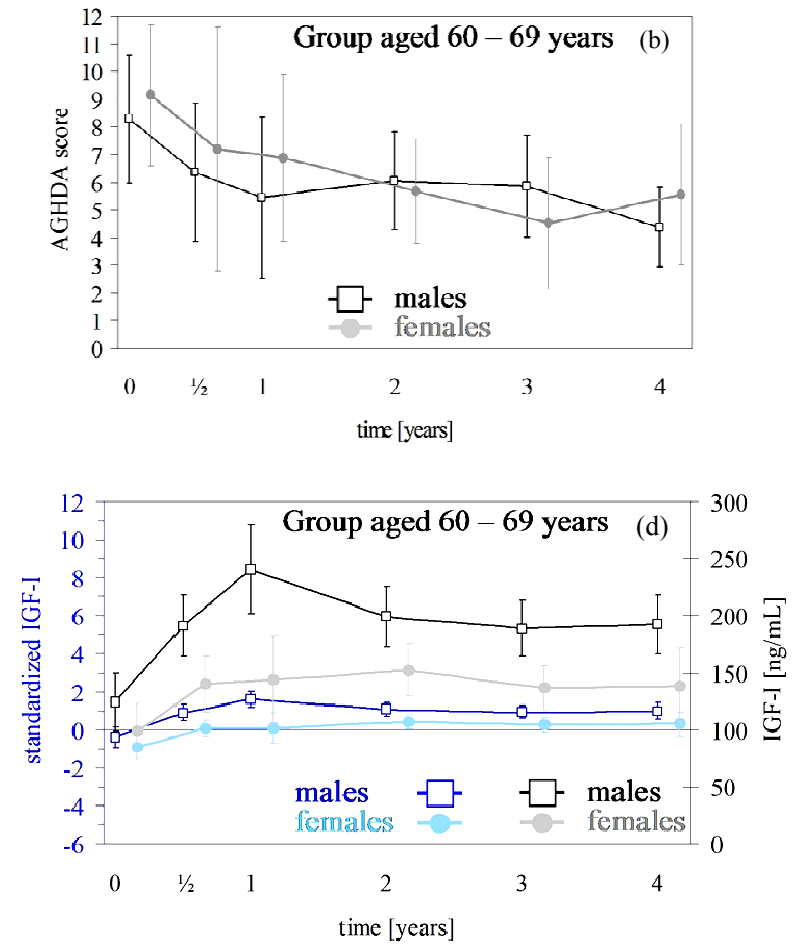

Figure 1. (a), (b) AGHDA scores (male: black; female: grey) with 95\% confidence intervals (CI) over a maximum of four years for a total of 298 females with 854 observations and 349 males with 978 observations. Time except for the baseline examination was rounded up to whole year but within the first year up to half-year. The $95 \% \mathrm{CI}$ are adjusted for correlated observations within patients. (c) and (d) IGF-I levels (male: black; female: grey) and standardized IGF-I levels (male: blue; female: light blue) with 95\% confidence intervals (CI) over a maximum of four years for a total of 272 females with 1150 observations and 303 male completers with 1345 observations. Time except for the baseline examination was rounded up to whole year but within the first year up to half-year. The $95 \%$ CI are adjusted for correlated observations within patients.

patients older than 60 years of age as well. Our results are confirmed by a recent metaanalysis of 11 eligible studies with a total of 534 patients [27]. However, only 2 of these 11 studies prospective, based on a randomized, placebo-controlled study design with a duration of $6(\mathrm{~N}=$ $15)$ or 12 months $(\mathrm{N}=62)$, respectively.

In our study both age groups, middle aged as well as older patients and genders had decreased QoL-AGHDAscores after one year of GH therapy than at baseline and this improvement remained up to four years. Interestingly, the improvement in HRQoL was restricted to the dose-finding phase $[13,28,29]$. The level of improvement was substantially the same across elderly and non-elderly $[13,15,16]$, but in contrast to our study, mostly cohorts of elderly were analysed in the metaanalysis only up to 12 months ( 8 studies $\mathrm{N}=422$ patients).

The benefit of the therapy for elderly is additionally supported by the non-impairment after the dose-finding phase and went confirm with other long-term studies of mixed age-groups up to nine years with smaller cohorts [29-35]. Gibney et al. [36] showed an improvement over a period of 10 years but only for a very small cohort $(\mathrm{n}=$ 11). Females improved more than males [28], in contrast to other findings [29], without any gender-differences. Kendall-Taylor et al. [37] found a greater impairment HRQoL in AO patients than in CO patients at baseline. Rosilio et al. [14] detected this difference after one year of GH-replacement, but not during the following year, that could be due to a very small number of $\mathrm{CO}$ patients $[38,39]$. However, after four years of GH replacement, we found a greater improvement in $\mathrm{CO}$ patients in comparison to the AO cohort [40] in contrast to Bengtsson et al. [28]. They detected an improvement in HRQoL only in AO patients.

Previous long-term studies of GH replacement compared HRQoL values of different countries. KoltowskaHäggstrom and colleagues analysed 758 patients up to seven years [31]. HRQoL already improved during the first year and remained constant in the follow up. They compared their results with large cohorts from England/ Wales, the Netherlands, Spain and Sweden with a minimum duration of two years up to a maximum of seven years. HRQoL was impaired in comparison with healthy controls and improved in all countries. Saller et al. found no differences between the improvements in HRQoL of the Netherlands, Sweden and Germany [35]. 
Moock et al. [41] demonstrated no correlation between IGF-I serum concentration and AGHDA scores for a German cohort. The increase and normalization of IGF-Ilevels in the present analysis are consistent with many other studies [33,36,40,42-50]. A gender-related benefit was detected by others [29,51,52] and for long-term stud- ies as well [53-55]. This gender difference regarding IGF-I levels was present in our data but without confi- dence. The most likely reason might be the postmeno- pausal status in our patient goup. The rate of change re- garding standardized IGF-I values, however, was sub- stantially the same in males and females over both phases. In addition, the rate of change over the preservation phase was the same as for healthy males or females. Re- markably, although female and male patients aged 60 to 69 years were in or close to normal ranges at baseline we found a positive therapy effect on QoL in this age group. As mentioned in the result in elderly the GH dosage was significant lower than in the younger age groups.

In elderly, however, normal IGF-I levels are no excluding criteria of GHD presence [17]. Hilding et al. [56] observed normal IGF-I values at baseline with increasing age. The percentage of normal IGF-I baseline values increased from $4 \%$ of 20 - 39 years old patients up to $40 \%$ in the group over 60 years. It is well known that in the elderly GH secretion decreases, associated with a decline in IGF1 levels. Therefore, age-adjusted IGF-I SD-scores are necessary to be able to assess the treatment response to rhGH as in our study using IGF-I SD-scores established in a central laboratory with adequate reference ranges established in healthy controls even in the elderly.

This study also assessed the lipid profile and no change was found and went confirm with others [42,53,57]. Other studies detected a decrease for total cholesterol in all agegroups and both genders [15,46,54]. Generally, LDL-C showed a trend to decrease as described in some longterm studies of GH replacement therapy [36,58] also in patients over 65 years of age [59]. High baseline values or high dose of $\mathrm{GH}$ replacement could be reasonable for that. In the recent metaanalysis [27] treatment with $\mathrm{rhGH}$ in elderly showed a lowering effect on total and LDL cholesterol. Again, most of the patients $(\mathrm{N}=422$ out of 534 patients) were observed for 12 months or less. Moreover, blood glucose levels were independent of age, which is in line with four previous studies [36,42,53,57].

During GH therapy the BMI increased over the preservation phase without difference between elderly and non-elderly. Changes over dose-finding phase were very small and showed no gender-related differences [53,54,60]. However, constant BMI levels were measured by Giusti et al. [47]. In summary, our results in the elderly confirm the data of Spielhagen et al. [12] that demonstrated also no significant effects on total cholesterol, LDL-C or an- thropometric parameters like BMI in a long term observation. From this point of view, it is uncertain whether the previous reported beneficial effects of GH treatment lipids and body composition can be translated into decreased cardiovascular events or morbidity and mortality. However, another group demonstrated recently that two years of GH replacement decreased cardiovascular risk estimates approximately by half [61]. In this study male sex, high total and low HDL cholesterol levels are potential predictors of good response, whereas, in large epidemiological studies the addition of biomarker information did not affect the association of subjective health measures, like SF12 or QoL-AGHDA, with mortality, but significantly improved risk stratification. Thus, a combined assessment of self-reported subjective health and measured biomarkers may be useful to identify high-risk individuals for intensified monitoring [62].

One limitation of our study is the lack of a control group. For IGF-I, however, the zero level of standardized IGF-I may serve as an adequate comparison. Moreover, a quasi-control group within subjects was generated by separating the study period into dose-finding and presservation phase. If the change during the dose-finding phase is different from those over the preservation-phase, the specificity of the treatment effect will be supported. This was clearly met for IGF-I and AGHDA scores. A second limitation is the absence of the group aged 50 - 59 years. For this age group only assumptions can be made.

In conclusion, we have shown that HRQoL was improved not only in younger GHD patients but elderly perceived benefits as well, which have been confirmed by small sized randomized controlled trials as well as by a recent metaanalysis. Therefore, GH therapy should not only be offered to young and middle-aged GHD patients. There seems to be no age limitation in treating elderly GHD adults with GH, especially in view of QoL measures. Not only a long life but also to facilitate for growing old in dignity should be the ambition of medical therapy. Whereas, the question, if the effect of long term GH treatment in the elderly on cardiometabolic outcomes is clinically relevant, remains under discussion and might be better solved in further randomized controlled trials.

\section{Acknowledgements}

\subsection{Disclosure Statement}

This paper uses data of KIMS, an international metabolic database, supported by Pfizer. Christin Spielhagen, Christian Schwahn, Kristin Arp, Jörn Moock, Nele Friedrich, Matthias Nauck and Thomas Kohlmann declare no potential conflicting interests. Michael Buchfelder and Henri Wallaschofski are members of the National German and also of the International KIMS Board. Michael Buchfelder is also a member of the Strategic Advisory Board 
of KIMS. Maria Koltowska-Häggström is currently employed by Pfizer.

\subsection{Acknowledgements}

We thank the participants of KIMS Germany who provide the data on their patients and the colleagues working at KIGS/KIMS/ACROSTUDY Medical Outcomes in Stockholm. Without their commitment, support and daily work the KIMS database would not exist and many studies would have never happened. KIMS is supported by Pfizer.

Moreover, we would like to express our thanks to the participants of KIMS in Germany who provided the data on their patients and to the colleagues working at KIGS/KIMS/Acrostudy Medical Outcomes in Karlsruhe and Stockholm. Without their commitment, support and daily hard work the KIMS database would not exist. (Dr. I. Harsch, University of Erlangen; Prof. Dr. M. Weber, University of Mainz; Prof. Dr. C. Kasperk, Prof. Dr. P. Nawroth, University of Heidelberg; Dr. C. Auernhammer, University of Munich; Prof. Dr. K. Mann, University of Essen; Dr. J. Krug, Clinical Center St. Georg Leipzig; Prof. Dr. R. F. Hampel, University of Rostock; Prof. Dr. U. Tuschy, University of Erfurt; Prof. Dr. N. Stahnke, Endokrinologikum Hamburg; Prof. Dr. H.-U. Häring, University of Tübingen; Dr, H. Mönig, University of Kiel; Prof. Dr. D. Klingmüller, University of Bonn; Prof. Dr. P. Ball, Lübeck; Dr. J. Ittner, Augsburg; Dr. C. Kerber, HELIOS Schwerin; Dr. R. Gellner, University of Münster; Prof. Dr. K.-J. Gräf, Endokrinologikum Berlin; Prof. Dr. G. Stalla, Max-Planck-Institute Munich; Prof. Dr. F.-U. Beil, UKE Hamburg; Dr. J. Santen, Dr. R. Engelbach, Frankfurt; Dr. M. Faust, University of Cologne; Dr. K. Reschke, University of Magdeburg; Prof. Dr. P. Weisweiler, Munich; Dr. M. Droste, Oldenburg; Dr. U. Deuß, Cologne; Dr. C. Terkamp, MHH Hanover; Dr. K. Ventzke, Bremen; Prof. Dr. H.M. Schulte, Endokrinologikum Hamburg; Dr. J. Schopohl, University of Munich; Dr. C. Jaursch-Hanke, DKD GFF Wiesbaden; Dr. M. Gruber, University of Dresden; Prof. Dr. M. Stumvoll, University of Leipzig; Prof. Dr. O.A. Müller, "RotKreuz" Hospital Munich; Prof. Dr. H. Stracke, University of Giessen; Dr. W. Faßbender, Hospital zum Hl. Geist Kempen; Dr. E. Jochum, Krankenhaus der Barmherzigen Brüder, Trier; Dr. F. Demtröder, Städtisches Klinikum Dortmund gGmbH; Prof. Dr. T. H. Schürmeyer, Mutterhaus der Borromäerinnen Trier; Dr. F. Schröder, Brandenburg; Prof. Dr. K. Badenhoop, University of Frankfurt; Prof. Dr. W. Karges, University of Aachen; Prof. Dr. J. Seufert, University of Freiburg; Prof. Dr. J. Hensen, Klinikum Nordstadt Hanover; Prof. Dr. U. Bogner, Berlin; Dr. R. Gutekunst, Lübeck; Prof. Dr. P. Kann, University of Marburg; Dr. U. Schröder, Endokri- nologikum Hanover; Dr. U. Plöckinger, University of Berlin; Dr. K. Wiener, Cottbus; Dr. J. Feldkamp, Bielefeld; Dr. A. Hoffmann, Cologne; Dr. J. Wildbrett, Dresden; Dr. H. Dirks, Bremen; Prof. Dr. U. Schneyer, University of Halle; Dr. M. Wolf, Hospital BietigheimBissingen; Dr. V. Hector, Hamburg; Dr. A. Figge, University of Bochum; Prof. Dr. A. Hübner, University of Dresden; Dr. H.J. Kröhne, Jena; Dr. C. Weber, Halberstadt; Dr. W. Omran, Mainz; Dr. B. Gerbert, Endokrinologikum Dresden.)

\section{REFERENCES}

[1] A. Binnerts, P. Deurenberg, G. R. Swart, J. H. Wilson and S. W. Lamberts, "Body Composition in Growth HormoneDeficient Adults," The American Journal of Clinical Nutrition, Vol. 55, No. 5, 1992, pp. 918-923.

[2] R. D. Murray, J. E. Adams and S. M. Shalet, "Adults with Partial Growth Hormone Deficiency Have an Adverse Body Composition," The Journal of Clinical Endocrinology \& Metabolism, Vol. 89, No. 4, 2004, pp. 15861591. doi:10.1210/jc.2003-030761

[3] S. J. Holmes, G. Economou, R. W. Whitehouse, J. E. Adams and S. M. Shalet, "Reduced Bone Mineral Density in Patients with Adult Onset Growth Hormone Deficiency," The Journal of Clinical Endocrinology \& Metabolism, Vol. 78, No. 3, 1994, pp. 669-674. doi:10.1210/jc.78.3.669

[4] H. de Boer, G. J. Blok and E. A. Van der Veen, "Clinical Aspects of Growth Hormone Deficiency in Adults," Endocrine Reviews, Vol. 16, No. 1, 1995, pp. 63-86. doi:10.1210/er.16.1.63

[5] A. Sanmarti, A. Lucas, F. Hawkins, S. M. Webb and A. Ulied, "Observational Study in Adult Hypopituitary Patients with Untreated Growth Hormone Deficiency (Oda Study). Socio-Economic Impact and Health Status. Collaborative Oda (Observational Gh Deficiency in Adults) Group," European Journal of Endocrinology, Vol. 141, No. 5, 1999, pp. 481-489. doi:10.1530/eje.0.1410481

[6] A. Bohdanowicz-Pawlak, J. Szymczak, J. Bladowska, G. Bednarek-Tupikowska, B. Bidzinska and A. Milewicz, "Risk Factors of Cardiovascular Disease in Gh-Deficient Adults with Hypopituitarism: A Preliminary Report," Medical Science Monitor, Vol. 12, No. 2, 2006, pp. CR 75-CR80.

[7] M. Gola, S. Bonadonna, M. Doga and A. Giustina, "Clinical Review: Growth Hormone and Cardiovascular Risk Factors," The Journal of Clinical Endocrinology \& Metabolism, Vol. 90, No. 3, 2005, pp. 1864-1870. doi: $10.1210 /$ jc. $2004-0545$

[8] P. Maison and P. Chanson, "Cardiac Effects of Growth Hormone in Adults with Growth Hormone Deficiency: A Meta-Analysis," Circulation, Vol. 108, No. 21, 2003, pp. 2648-2652. doi:10.1161/01.CIR.0000100720.01867.1D

[9] T. Rosen, G. Johannsson, J. O. Johansson and B. A. Bengtsson, "Consequences of Growth Hormone Deficiency in Adults and the Benefits and Risks of Recombinant Human Growth Hormone Treatment. A Review Pa- 
per," Hormone Research, Vol. 43, No. 1-3, 1995, pp. 9399. doi:10.1159/000184245

[10] M. Koltowska-Haggstrom, S. Hennessy, A. F. Mattsson, J. P. Monson and P. Kind, "Quality of Life Assessment of Growth Hormone Deficiency in Adults (Qol-Aghda): Comparison of Normative Reference Data for the General Population of England and Wales with Results for Adult Hypopituitary Patients with Growth Hormone Deficiency," Hormone Research, Vol. 64, No. 1, 2005, pp. 4654. doi:10.1159/000087444

[11] G. A. McGauley, "Quality of Life Assessment before and after Growth Hormone Treatment in Adults with Growth Hormone Deficiency," Acta Paediatrica Scandinavica. Supplement, Vol. 356, 1989, pp. 70-74.

[12] C. Spielhagen, C. Schwahn, K. Moller, N. Friedrich, T. Kohlmann, J. Moock, et al., "The Benefit of Long-Term Growth Hormone (Gh) Replacement Therapy in Hypopituitary Adults with Gh Deficiency: Results of the German Kims Database," Growth Hormone \& IGF Research, Vol. 21, No. 1, 2011, pp. 1-10. doi:10.1016/j.ghir.2010.10.005

[13] J. P. Monson and P. Jonsson, "Aspects of Growth Hormone (Gh) Replacement in Elderly Patients with Gh Deficiency: Data from Kims," Hormone Research, Vol. 60, No. S1, 2003, pp. 112-120.

[14] M. Rosilio, W. F. Blum, D. J. Edwards, E. P. Shavrikova, D. Valle, S. W. Lamberts, et al., "Long-Term Improvement of Quality of Life During Growth Hormone (Gh) Replacement Therapy in Adults with Gh Deficiency, as Measured by Questions on Life Satisfaction-Hypopituitarism (Qls-H)," The Journal of Clinical Endocrinology \& Metabolism, Vol. 89, No. 4, 2004, pp. 1684-1693. doi:10.1210/jc.2003-030134

[15] J. P. Monson, R. Abs, B. A. Bengtsson, H. Bennmarker, U. Feldt-Rasmussen, E. Hernberg-Stahl, et al., "Growth Hormone Deficiency and Replacement in Elderly Hypopituitary Adults. Kims Study Group and the Kims International Board. Pharmacia and Upjohn International Metabolic Database," Clinical Endocrinology (Oxford), Vol. 53, No. 3, 2000, pp. 281-289. doi:10.1046/j.1365-2265.2000.01104.X

[16] U. Feldt-Rasmussen, P. Wilton and P. Jonsson, “Aspects of Growth Hormone Deficiency and Replacement in Elderly Hypopituitary Adults," Growth Hormone \& IGF Research, Vol. 14, Suppl. A, 2004, pp. S51-S58.

[17] M. E. Molitch, D. R. Clemmons, S. Malozowski, G. R. Merriam, S. M. Shalet, M. L. Vance, et al., "Evaluation and Treatment of Adult Growth Hormone Deficiency: An Endocrine Society Clinical Practice Guideline," The Journal of Clinical Endocrinology \& Metabolism, Vol. 91, No. 5, 2006, pp. 1621-1634. doi:10.1210/jc.2005-2227

[18] K. K. Ho, "Consensus Guidelines for the Diagnosis and Treatment of Adults with Gh Deficiency Ii: A Statement of the Gh Research Society in Association with the European Society for Pediatric Endocrinology, Lawson Wilkins Society, European Society of Endocrinology, Japan Endocrine Society, and Endocrine Society of Australia," European Journal of Endocrinology, Vol. 157, No. 6, 2007, pp. 695-700. doi:10.1530/EJE-07-0631

[19] S. P. McKenna, L. C. Doward, J. Alonso, T. Kohlmann,
M. Niero, L. Prieto, et al., "The Qol-Aghda: An Instrument for the Assessment of Quality of Life in Adults with Growth Hormone Deficiency," Quality of Life Research, Vol. 8, No. 4, 1999, pp. 373-383. doi:10.1023/A:1008987922774

[20] W. T. Friedewald, R. I. Levy and D. S. Fredrickson, "Estimation of the Concentration of Low-Density Lipoprotein Cholesterol in Plasma, without Use of the Preparative Ultracentrifuge," Clinical Chemistry, Vol. 18, No. 6, 1972, pp. 499-502.

[21] R. F. Lie, J. M. Schmitz, K. J. Pierre and N. Gochman, "Cholesterol Oxidase-Based Determination, by Continuous-Flow Analysis, of Total and Free Cholesterol in Serum," Clinical Chemistry, Vol. 22, No. 10, 1976, pp. 1627-1630.

[22] M. F. Lopes-Virella, P. Stone, S. Ellis and J. A. Colwell, "Cholesterol Determination in High-Density Lipoproteins Separated by Three Different Methods," Clinical Chemistry, Vol. 23, No. 5, 1977, pp. 882-884.

[23] P. Fossati and L. Prencipe, "Serum Triglycerides Determined Colorimetrically with an Enzyme That Produces Hydrogen Peroxide," Clinical Chemistry, Vol. 28, No. 10, 1982, pp. 2077-2080.

[24] D. Hedeker and R. D. Gibbons, "Application of RandomEffects Pattern-Mixture Models for Missing Data in Longitudinal Studies," Psychological Methods, Vol. 2, No. 1, 1997, pp. 64-78. doi:10.1037/1082-989X.2.1.64

[25] J. D. Singer and J. B. Willett, "Applied Longitudinal Data Analysis: Modeling Change and Event Occurrence," Oxford University Press, Oxford, 2003. doi:10.1093/acprof:oso/9780195152968.001.0001

[26] A. Skrondal and S. Rabe-Hesketh, "Generalized Latent Variable Modeling: Multilevel, Longitudinal, and Structural Equation Models," Chapman \& Hall/CRC, Boca Raton, London, 2004. doi:10.1201/9780203489437

[27] N. E. Kokshoorn, N. R. Biermasz, F. Roelfsema, J. W. Smit, A. M. Pereira and J. A. Romijn, "Gh Replacement Therapy in Elderly Gh-Deficient Patients: A Systematic Review," European Journal of Endocrinology, Vol. 164, No. 5, 2011, pp. 657-665. doi:10.1530/EJE-10-1170

[28] B. A. Bengtsson, R. Abs, H. Bennmarker, J. P. Monson, U. Feldt-Rasmussen, E. Hernberg-Stahl, et al., "The Effects of Treatment and the Individual Responsiveness to Growth Hormone (Gh) Replacement Therapy in 665 GhDeficient Adults. Kims Study Group and the Kims International Board," The Journal of Clinical Endocrinology \& Metabolism, Vol. 84, No. 11, 1999, pp. 3929-3935. doi:10.1210/jc.84.11.3929

[29] J. Svensson, A. Mattsson, T. Rosen, L. Wiren, G. Johannsson, B. A. Bengtsson, et al., "Three-Years of Growth Hormone (Gh) Replacement Therapy in Gh-Deficient Adults: Effects on Quality of Life, Patient-Reported Outcomes and Healthcare Consumption," Growth Hormone \& IGF Research, Vol. 14, No. 3, 2004, pp. 207-215. doi:10.1016/j.ghir.2003.12.001

[30] L. Wiren, B. A. Bengtsson and G. Johannsson, "Beneficial Effects of Long-Term Gh Replacement Therapy on Quality of Life in Adults with Gh Deficiency," Clinical Endocrinology (Oxford), Vol. 48, No. 5, 1998, pp. 613- 
620. doi:10.1046/j.1365-2265.1998.00462.x

[31] M. Koltowska-Haggstrom, A. F. Mattsson, J. P. Monson, P. Kind, X. Badia, F. F. Casanueva, et al., "Does LongTerm Gh Replacement Therapy in Hypopituitary Adults with Gh Deficiency Normalise Quality of Life?" European Journal of Endocrinology, Vol. 155, No. 1, 2006, pp. 109-119. doi:10.1530/eje.1.02176

[32] F. J. Gilchrist, R. D. Murray and S. M. Shalet, "The Effect of Long-Term Untreated Growth Hormone Deficiency (Ghd) and 9 Years of Gh Replacement on the Quality of Life (Qol) of Gh-Deficient Adults," Clinical Endocrinology (Oxford), Vol. 57, No. 3, 2002, pp. 363-370. doi:10.1046/j.1365-2265.2002.01608.x

[33] M. E. Wallymahmed, P. Foy, D. Shaw, R. Hutcheon, R. H. Edwards and I. A. MacFarlane, "Quality of Life, Body Composition and Muscle Strength in Adult Growth Hormone Deficiency: The Influence of Growth Hormone Replacement Therapy for Up to 3 Years," Clinical Endocrinology (Oxford), Vol. 47, No. 4, 1997, pp. 439-446. doi:10.1046/j.1365-2265.1997.2801076.x

[34] J. Verhelst, R. Abs, M. Vandeweghe, J. Mockel, J. J. Legros, G. Copinschi, et al., "Two Years of Replacement Therapy in Adults with Growth Hormone Deficiency," Clinical Endocrinology (Oxford), Vol. 47, No. 4, 1997, pp. 485-494. doi:10.1046/j.1365-2265.1997.3041112.x

[35] B. Saller, A. F. Mattsson, P. H. Kann, H. P. Koppeschaar, J. Svensson, M. Pompen, et al., "Healthcare Utilization, Quality of Life and Patient-Reported Outcomes During Two Years of Gh Replacement Therapy in Gh-Deficient Adults-Comparison between Sweden, the Netherlands and Germany," European Journal of Endocrinology, Vol. 154, No. 6, 2006, pp. 843-850. doi:10.1530/eje.1.02149

[36] J. Gibney, J. D. Wallace, T. Spinks, L. Schnorr, A. Ranicar, R. C. Cuneo, et al., "The Effects of 10 Years of Recombinant Human Growth Hormone (GH) in Adult GHDeficient Patients," The Journal of Clinical Endocrinology \& Metabolism, Vol. 84, No. 8, 1999, pp. 2596- 2602. doi:10.1210/jc.84.8.2596

[37] P. Kendall-Taylor, P. J. Jonsson, R. Abs, E. M. Erfurth, M. Koltowska-Haggstrom, D. A. Price, et al., "The Clinical, Metabolic and Endocrine Features and the Quality of Life in Adults with Childhood-Onset Craniopharyngioma Compared with Adult-Onset Craniopharyngioma," European Journal of Endocrinology, Vol. 152, No. 4, 2005, pp. 557-567. doi:10.1530/eje.1.01877

[38] R. Abs, B. A. Bengtsson, E. Hernberg-Stahl, J. P. Monson, J. P. Tauber, P. Wilton, et al., "GH Replacement in 1034 Growth Hormone Deficient Hypopituitary Adults: Demographic and Clinical Characteristics, Dosing and Safety," Clinical Endocrinology, Vol. 50, No. 6, 1999, pp. 703-713. doi:10.1046/j.1365-2265.1999.00695.x

[39] E. Hernberg-Stahl, A. Luger, R. Abs, B. A. Bengtsson, U. Feldt-Rasmussen, P. Wilton, et al., "Healthcare Consumption Decreases in Parallel with Improvements in Quality of Life During GH Replacement in Hypopituitary Adults with GH Deficiency," Journal of Clinical Endocrinology Metabolism, Vol. 86, No. 11, 2001, pp. 5277-5281. doi:10.1210/jc.86.11.5277

[40] R. D. Murray, C. J. Skillicorn, S. J. Howell, C. A. Lissett,
A. Rahim, L. E. Smethurst, et al., "Influences on Quality of Life in GH Deficient Adults and Their Effect on Response to Treatment," Clinical Endocrinology, Vol. 51, No. 5, 1999, pp. 565-573.

doi:10.1046/j.1365-2265.1999.00838.x

[41] J. Moock, C. Albrecht, N. Friedrich, H. Volzke, M. Nauck, M. Koltowska-Haggstrom, et al., "Health-Related Quality of Life and IGF-1 in GH-Deficient Adult Patients on GH Replacement Therapy: Analysis of the German KIMS Data and the Study of Health in Pomerania," European Journal of Endocrinology, Vol. 160, No. 1, 2009, pp. 17-24. doi:10.1530/EJE-08-0738

[42] H. M. Whitehead, C. Boreham, E. M. McIlrath, B. Sheridan, L. Kennedy, A. B. Atkinson, et al., "Growth Hormone Treatment of Adults with Growth Hormone Deficiency: Results of a 13-Month Placebo Controlled CrossOver Study," Clinical Endocrinology, Vol. 36, No. 1, 1992, pp. 45-52. doi:10.1111/j.1365-2265.1992.tb02901.x

[43] M. Degerblad, O. Almkvist, R. Grunditz, K. Hall, L. Kaijser, E. Knutsson, et al., "Physical and Psychological Capabilities During Substitution Therapy with Recombinant Growth Hormone in Adults with Growth Hormone Deficiency," Acta Endocrinologica (Copenhagen), Vol. 123, No. 2, 1990, pp. 185-193.

[44] G. Johannsson, R. Bjarnason, M. Bramnert, L. M. Carlsson, M. Degerblad, P. Manhem, et al., "The Individual Responsiveness to Growth Hormone (GH) Treatment in GH-Deficient Adults Is Dependent on the Level of GHBinding Protein, Body Mass Index, Age, and Gender," Journal of Clinical Endocrinology Metabolism, Vol. 81, No. 4, 1996, pp. 1575-1581. doi:10.1210/jc.81.4.1575

[45] P. V. Carroll, R. Littlewood, A. J. Weissberger, P. Bogalho, G. McGauley, P. H. Sonksen, et al., "The Effects of Two Doses of Replacement Growth Hormone on the Biochemical, Body Composition and Psychological Profiles of Growth Hormone-Deficient Adults," European Journal of Endocrinology, Vol. 137, No. 2, 1997, pp. 146-153. doi:10.1530/eje.0.1370146

[46] R. C. Cuneo, S. Judd, J. D. Wallace, D. Perry-Keene, H. Burger, S. Lim-Tio, et al., "The Australian Multicenter Trial of Growth Hormone (GH) Treatment in GH-Deficient Adults," Journal of Clinical Endocrinology Metabolism, Vol. 83, No. 1, 1998, pp. 107-116. doi:10.1210/jc.83.1.107

[47] M. Giusti, I. Meineri, D. Malagamba, C. M. Cuttica, G. Fattacciu, U. Menichini, et al., "Impact of Recombinant Human Growth Hormone Treatment on Psychological Profiles in Hypopituitary Patients with Adult-Onset Growth Hormone Deficiency," European Journal of Clinical Investigation, Vol. 28, No. 1, 1998, pp. 13-19. doi:10.1046/j.1365-2362.1998.00239.x

[48] H. B. Baum, L. Katznelson, J. C. Sherman, B. M. Biller, D. L. Hayden, D. A. Schoenfeld, et al., "Effects of Physiological Growth Hormone (GH) Therapy on Cognition and Quality of Life in Patients with Adult-Onset GH Deficiency," Journal of Clinical Endocrinology Metabolism, Vol. 83, No. 9, 1998, pp. 3184-3189. doi:10.1210/jc.83.9.3184

[49] G. Johannsson, T. Rosen and B. A. Bengtsson, "Individualized Dose Titration of Growth Hormone (GH) During 
GH Replacement in Hypopituitary Adults," Clinical Endocrinology, Vol. 47, No. 5, 1997, pp. 571-581. doi:10.1046/j.1365-2265.1997.3271123.x

[50] S. G. Thomas, J. G. Esposito and S. Ezzat, "Exercise Training Benefits Growth Hormone (GH)-Deficient Adults in the Absence or Presence of GH Treatment," Journal of Clinical Endocrinology Metabolism, Vol. 88, No. 12, 2003, pp. 5734-5738. doi:10.1210/jc.2003-030632

[51] S. Ezzat, S. Fear, R. C. Gaillard, C. Gayle, H. Landy, S. Marcovitz, et al., "Gender-Specific Responses of Lean Body Composition and Non-Gender-Specific Cardiac Function Improvement after GH Replacement in GH-Deficient Adults," Journal of Clinical Endocrinology Metabolism, Vol. 87, No. 6, 2002, pp. 2725-2733. doi: $10.1210 /$ jc. 87.6 .2725

[52] I. A. Malik, P. Foy, M. Wallymahmed, J. P. Wilding and I. A. MacFarlane, "Assessment of Quality of Life in Adults Receiving Long-Term Growth Hormone Replacement Compared to Control Subjects," Clinical Endocrinology, Vol. 59, No. 1, 2003, pp. 75-81 doi:10.1046/j.1365-2265.2003.01799.x

[53] A. Chrisoulidou, S. A. Beshyah, O. Rutherford, T. J. Spinks, J. Mayet, P. Kyd, et al., "Effects of 7 Years of Growth Hormone Replacement Therapy in Hypopituitary Adults," Journal of Clinical Endocrinology Metabolism, Vol. 85, No. 10, 2000, pp. 3762-3769. doi: $10.1210 /$ jc. 85.10 .3762

[54] G. Götherström, J. Svensson, J. Koranyi, M. Alpsten, I. Bosaeus, B. Bengtsson, et al., "A Prospective Study of 5 Years of GH Replacement Therapy in GH-Deficient Adults: Sustained Effects on Body Composition, Bone Mass, and Metabolic Indices," Journal of Clinical Endocrinology Metabolism, Vol. 86, No. 10, 2001, pp. 46574665. doi:10.1210/jc.86.10.4657

[55] J. Koranyi, J. Svensson, G. Gotherstrom, K. S. Sunnerhagen, B. Bengtsson and G. Johannsson, "Baseline Characteristics and the Effects of Five Years of GH Replacement Therapy in Adults with GH Deficiency of Childhood or Adulthood Onset: A Comparative, Prospective Study," Journal of Clinical Endocrinology Metabolism, Vol. 86, No. 10, 2001, pp. 4693-4699. doi: $10.1210 /$ jc. 86.10 .4693

[56] A. Hilding, K. Hall, I. L. Wivall-Helleryd, M. Saaf, A. L. Melin and M. Thoren, "Serum Levels of Insulin-Like
Growth Factor I in 152 Patients with Growth Hormone Deficiency, Aged 19-82 Years, in Relation to Those in Healthy Subjects," Journal of Clinical Endocrinology Metabolism, Vol. 84, No. 6, 1999, pp. 2013-2019. doi:10.1210/jc.84.6.2013

[57] T. Laursen, C. H. Gravholt, L. Heickendorff, J. Drustrup, A. M. Kappelgaard, J. O. Jorgensen, et al., "Long-Term Effects of Continuous Subcutaneous Infusion Versus Daily Subcutaneous Injections of Growth Hormone (GH) on the Insulin-Like Growth Factor System, Insulin Sensitivity, Body Composition, and Bone and Lipoprotein Metabolism in GH-Deficient Adults," Journal of Clinical Endocrinology Metabolism, Vol. 86, No. 3, 2001, pp. 1222-1228. doi:10.1210/jc.86.3.1222

[58] A. A. van der Klaauw, J. A. Romijn, N. R. Biermasz, J. W. Smit, J. van Doorn, O. M. Dekkers, et al., "Sustained Effects of Recombinant GH Replacement after 7 Years of Treatment in Adults with GH Deficiency," European Journal of Endocrinology, Vol. 155, No. 5, 2006, pp. 701-708. doi:10.1530/eje.1.02283

[59] C. Franco, G. Johannsson, B. A. Bengtsson and J. Svensson, "Baseline Characteristics and Effects of Growth Hormone Therapy over Two Years in Younger and Elderly Adults with Adult Onset GH Deficiency," Journal of Clinical Endocrinology Metabolism, Vol. 91, No. 11, 2006, pp. 4408-4414. doi:10.1210/jc.2006-0887

[60] A. F. Attanasio, P. C. Bates, K. K. Ho, S. M. Webb, R. J. Ross, C. J. Strasburger, et al., "Human Growth Hormone Replacement in Adult Hypopituitary Patients: Long-Term Effects on Body Composition and Lipid Status-3-Year Results from the HypoCCS Database," Journal of Clinical Endocrinology Metabolism, Vol. 87, No. 4, 2002, pp. 1600-1606. doi: $10.1210 /$ jc. 87.4 .1600

[61] H. Schneider, J. Klotsche, H. Wittchen, G. Stalla, J. Schopohl, P. Kann, et al., "Effects of Growth Hormone Replacement within the KIMS Survey on Estimated Cardiovascular Risk and Predictors of Risk Reduction in Patients with Growth Hormone Deficiency," Clinical Endocrinology, Vol. 75, No. 6, 2011, pp. 825-830.

[62] R. Haring, Y. S. Feng, J. Moock, H. Volzke, M. Dorr, M. Nauck, et al., "Self-Perceived Quality of Life Predicts Mortality Risk Better Than a Multi-Biomarker Panel, but the Combination of Both Does Best," BMC Medical Research Methodology, Vol. 11, 2011, p. 103. 